\title{
Histomorphometric study of the canine prostate during ageing and in cases of benign prostate hyperplasia
}

\author{
Nomeda Juodziukyniene, Albina Aniuliene \\ Department of Infectious Diseases, Veterinary Academy, \\ Lithuanian University of Health Sciences, LT- 47181 Kaunas, Lithuania \\ Nomeda.Juodziukyniene@1smuni.1t
}

Received: November 2, $2015 \quad$ Accepted: March 10, 2016

\begin{abstract}
Introduction: The aim of the study was to examine the percentage volume of epithelium, acini, and interstitial collagen in the nonhyperplastic canine prostate and in cases of epithelial and epithelial cystic hyperplasia. Material and Methods: A histomorphometric study of 39 prostates was performed using computer image analysis. Results: The highest percentage volume of epithelium was found in cases of epithelial hyperplasia (47.8 \%) and epithelial cystic hyperplasia was the correlate for acini $(48.97 \%)$. Epithelium decreased with dogs' age $(\mathrm{P}<0.01)$, whereas acini increased $(\mathrm{P}<0.01)$. Interstitial collagen varied only insignificantly across age groups, but collagen was higher $(12.1 \%)$ in the nonhyperplastic prostates. With age cystic formation progressed in the canine prostate, the percentage volume of epithelium decreased and that of acini increased, but this same parameter in prostatic collagen did not change distinctly. The epithelium percentage volume increased in cases of epithelial hyperplasia but the cystic variant caused an increase in acinar volume. Conclusion: As dogs age, cystic formation progresses in the prostate, therefore the volume of epithelium decreases and that of acini increases. The volume of prostatic collagen did not change distinctly with age, and was higher in normal prostates than in both epithelial and epithelial cystic hyperplastic glands.
\end{abstract}

Keywords: dog, age, prostate hyperplasia, epithelium, acini, collagen.

\section{Introduction}

Benign prostate hyperplasia $(\mathrm{BPH})$ in older men and dogs is one of the most common diseases. The aetiology and pathogenesis of the disease remain uncertain. The interaction between steroids $(8,10,17)$, peptide hormones (e.g. prolactin), the effect of some growth factors $(4,16,18)$, and changed sensitivity of prostatic tissue play important roles $(13,19)$. Canine prostatic stroma indicates that the whole prostate gland must be an androgen-sensitive organ, with the epithelium and stroma under the control of the hormone $(2,13)$. As suggested by O'Shea in 1962, the endocrine changes responsible for prostatic hyperplasia may be initiated early in adult canine life (15).

Canine BPH is characterised by diffuse epithelial (glandular) proliferation throughout the entire prostate $(12,15,16)$. Prostate hyperplasia in dogs can begin at two-to-three years of age, becoming cystic after four years of age with weaker stromal involvement $(1,4,6$, 9 ). The results of some studies show that canine BPH is present either grossly or microscopically in almost $100 \%$ of sexually-intact adult male dogs over the age of seven years $(9,10,13)$. The peripheral region of the canine prostate is little different from the periurethral region $(5,7,13)$. The acini in the peripheral region are grosser and more abundant than in the periurethral region, the ducts here are narrower and longer, and aberrant ducts can be found in this region. The canine prostate is grossly and microscopically homogeneous (16). It has been theorised that because of different tissue sensitivity to sexual hormones and various growth factors, BPH in the canine prostate involves the peripheral region more $(6,7)$. Strong relationships between some pathologies and prostate regions have not been established. Glandular tissues in the dorsocranial coliculus seminalis area are to a small degree more sensitive to oestrogens. Squamous metaplasia is more frequently found in the utriculus, coliculus seminalis, the prostatic part of the urethra, and the large prostatic ducts $(3,12)$. Hyperplasia is thought to be related to acinar basal cells, while 
neoplasia is held to be related to ductal basal cells (12). Their sensitivity to factors influencing hyperplastic or neoplastic growth is unequal $(8,9)$.

The aim of the study was to examine the percentage volume of epithelium, acini, and interstitial collagen in normal dogs' prostates and prostates presenting with epithelial and epithelial cystic hyperplasia, in animals ranging from 1 to 17 years of age and older.

\section{Material and Methods}

Animals and macroscopic examination. The prostate glands of 39 dogs were obtained at routine autopsy. The ages of the dogs ranged from 1 to 17 years. Dogs were divided into three age groups: young, with ages between $1-5$ years $(n=13)$; middle-aged, in which dogs were between 6 and 10 years old $(n=13)$; and old, that is dogs aged 11-17 years $(n=13)$. Enlargement was evaluated by the index of the prostate: the weight of the prostate in grammes was divided by the weight of the dog in kilogrammes. Prostates were not considered enlarged if their indexes did not exceed 0.7 .

Histological examination. Each prostate gland was sagitally sectioned in such a way that the peripheral and central parts would appear in one specimen. The tissues were fixed in $10 \%$ formalin $(\mathrm{pH} 7.3)$ and processed for light microscopy. Sections of $5 \mu \mathrm{m}$ thickness were cut and stained with haematoxylin and eosin (HE) and Sirius Red according to standard histological techniques.

Morphometric analysis of epithelium, collagen, and acini. Using an image analysis system (Quantimet 520, Cambridge Instruments, U.K.) and software developed at the Laboratory of Cardiac Pathology, Institute of Cardiology, Lithuanian University of Health Sciences, Syrius Red-stained sections were analysed. The image analysis system was calibrated using a Reichert-Jung rule. The percentage volumes of epithelium, collagen, and acini were determined in each section of the peripheral portion of the prostatic ductal system (except inflammatory tissue). There were 70 fields of size $0.3515 \mathrm{~mm}^{2}$ quantified in each section using $125 \times$ magnification. Overall, there were 2730 fields estimated.

Statistical analysis. In order to compare histomorphometric parameters between two or more groups, a two-factor analysis of variance (ANOVA) and evaluation of the dispersions of morphometric parameters of the group and of each investigation object separately (nested design) were applied. Using this method, the changes in the prostate structures in separate age groups, in the normal prostate, and in cases of epithelial and epithelial cystic hyperplasia were measured. Student's $t$-test was used to find statistical differences between groups. Differences at the value of $\mathrm{P}<0.05$ were considered significant. Linear and non-linear regression analyses were used to measure the interrelations between prostate structure elements and dog age and prostate index. Using the regression analysis method, the correlations between epithelium, acini, and collagen percentage volume and prostate size were measured.

\section{Results}

Nonhyperplastic prostates (nonH) were in the form of tubular alveolar glands. The alveolar epithelium was columnar, with basally-located nuclei and infolding into the lumen in the oval acini. The epithelium lining the duct was cuboidal and regular in size. Histological diagnosis of epithelial hyperplasia (EHP) was based upon the criterion of larger alveoli and more cells in the alveoli, i.e. proliferation and papillation of secretory epithelial cells in the lumen of acini and ducts. Epithelial cystic hyperplasia (ECHP) was characterised by areas of glandular hyperplasia in which the acini were dilated and cystic, and the epithelium was atrophic and attenuated.

The percentage volume of epithelium, acini, and interstitial collagen in the prostates of young, middleaged, and old dogs, in nonhyperplastic prostates as well as in cases of EHP and ECHP were analysed and compared.

The percentage volumes of epithelium were different in all age groups $(\mathrm{P}<0.01)$. The highest percentage volume was found in the prostates of young dogs (between one and five years old) (48.1\%). A lower percentage volume was found in the prostates of middle-aged dogs (between six and ten years old) $(43.6 \%)$, and the lowest percentage volume was found in the prostates of the oldest dogs (eleven years and older) $(40.9 \%)$ (Fig. 1). The percentage volume of epithelium decreased in ageing dogs (Fig. 3.).

The percentage volumes of epithelium in normal and hyperplastic prostates differed reliably $(\mathrm{P}<0.01)$. The highest percentage volume of epithelium was found in cases of EHP (47.8\%), the lowest was in cases of ECHP $(40.2 \%)$, and the medium volume was in prostates with normal histological structure $(45.2 \%)$ (Fig. 2).

The percentage volumes of acini were also found to be different in all age groups. Contrary to the case of the percentage volume of epithelium that of acini increased over the dogs' lives $(\mathrm{P}<0.01): 41 \%$ in young dogs, $45.1 \%$ in middle-aged dogs, and $48.5 \%$ in the oldest dogs. The acini of the prostates became wider and the percentage volume of acini progressed with the dogs' ageing.

The highest percentage volume of acini was found in cases of ECHP (48.97\%), and it differed significantly from its counterpart in the prostates of normal histological structure. 


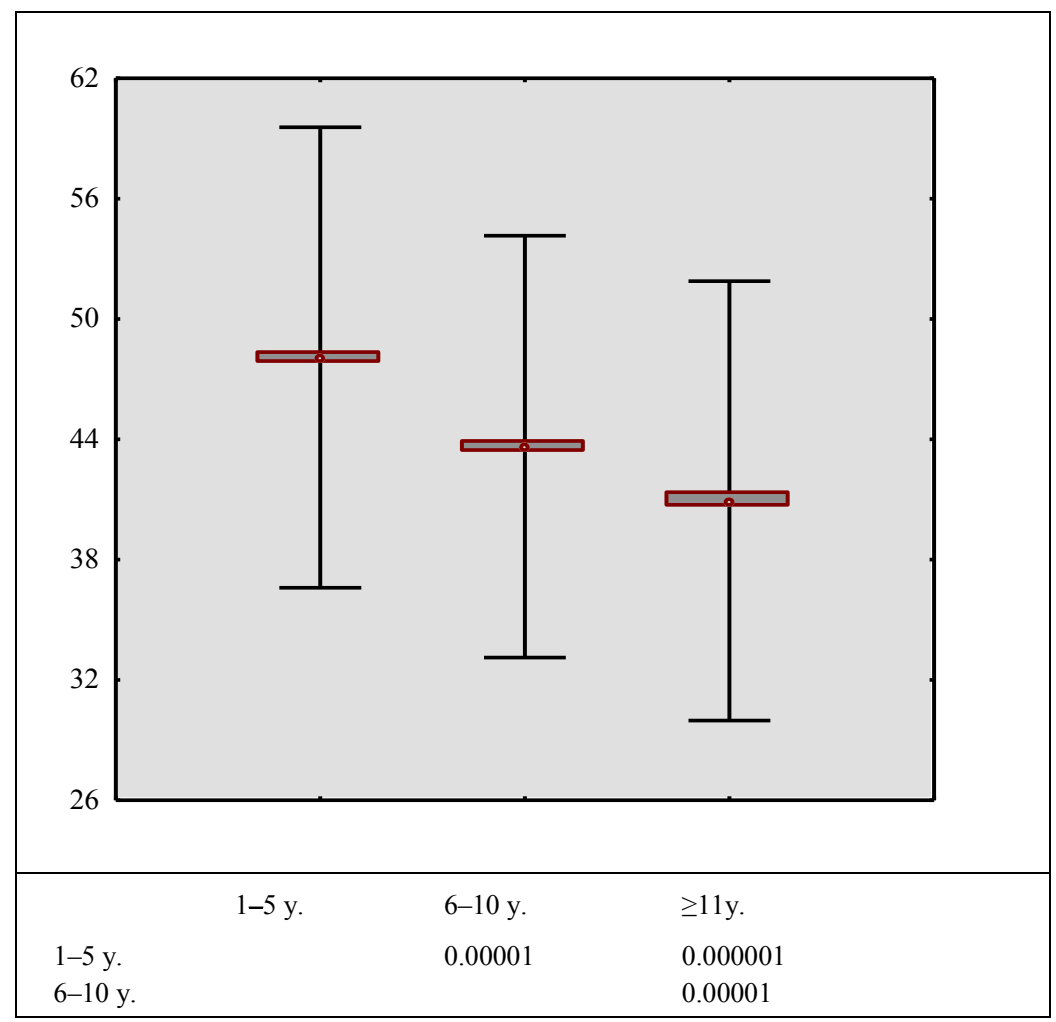

Fig. 1. The percentage volume of epithelium in dogs of different ages (mean, standard error, standard deviation, and $\mathrm{P}$ value)

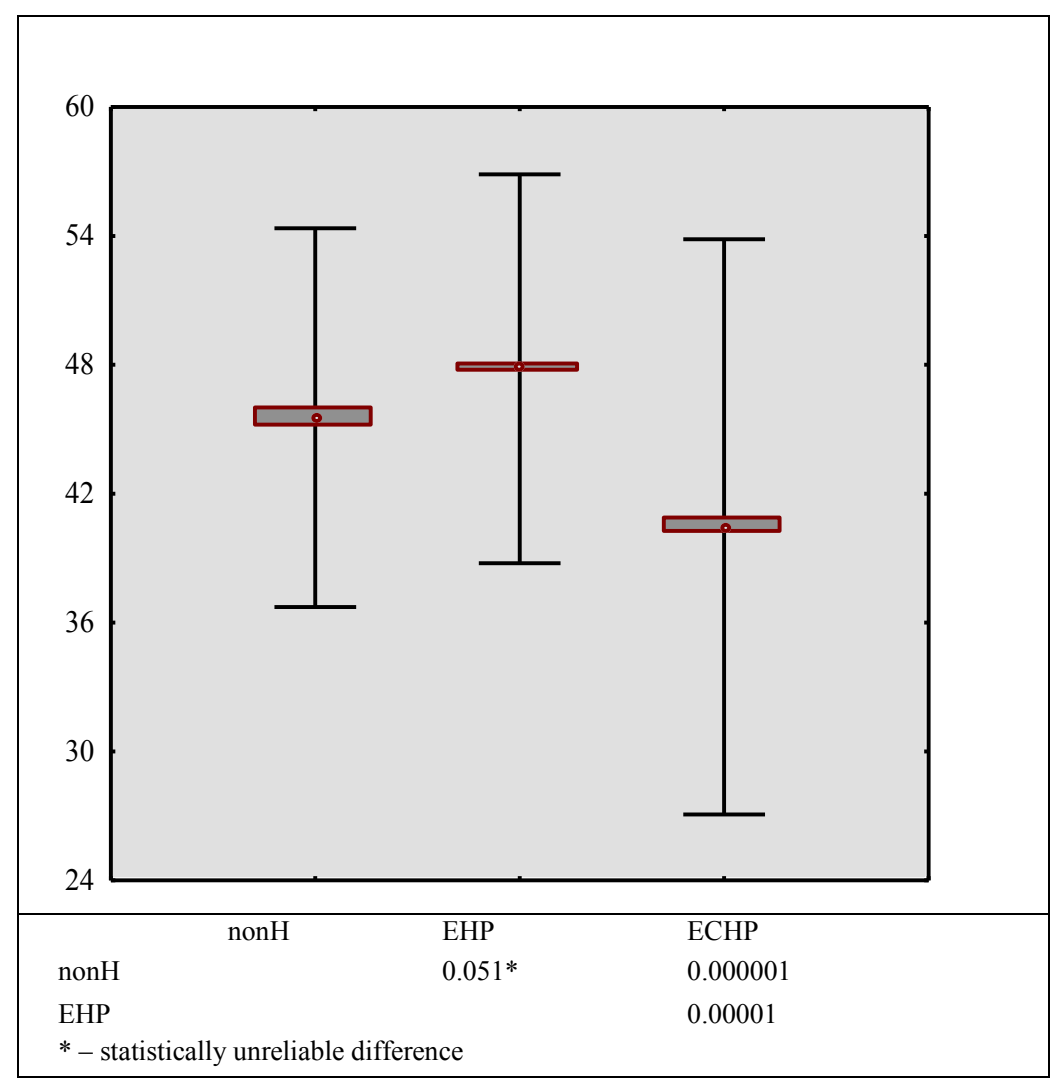

Fig. 2. The percentage volume of epithelium in nonhyperplastic and hyperplastic canine prostates (mean, standard error, standard deviation, and $\mathrm{P}$ value) 


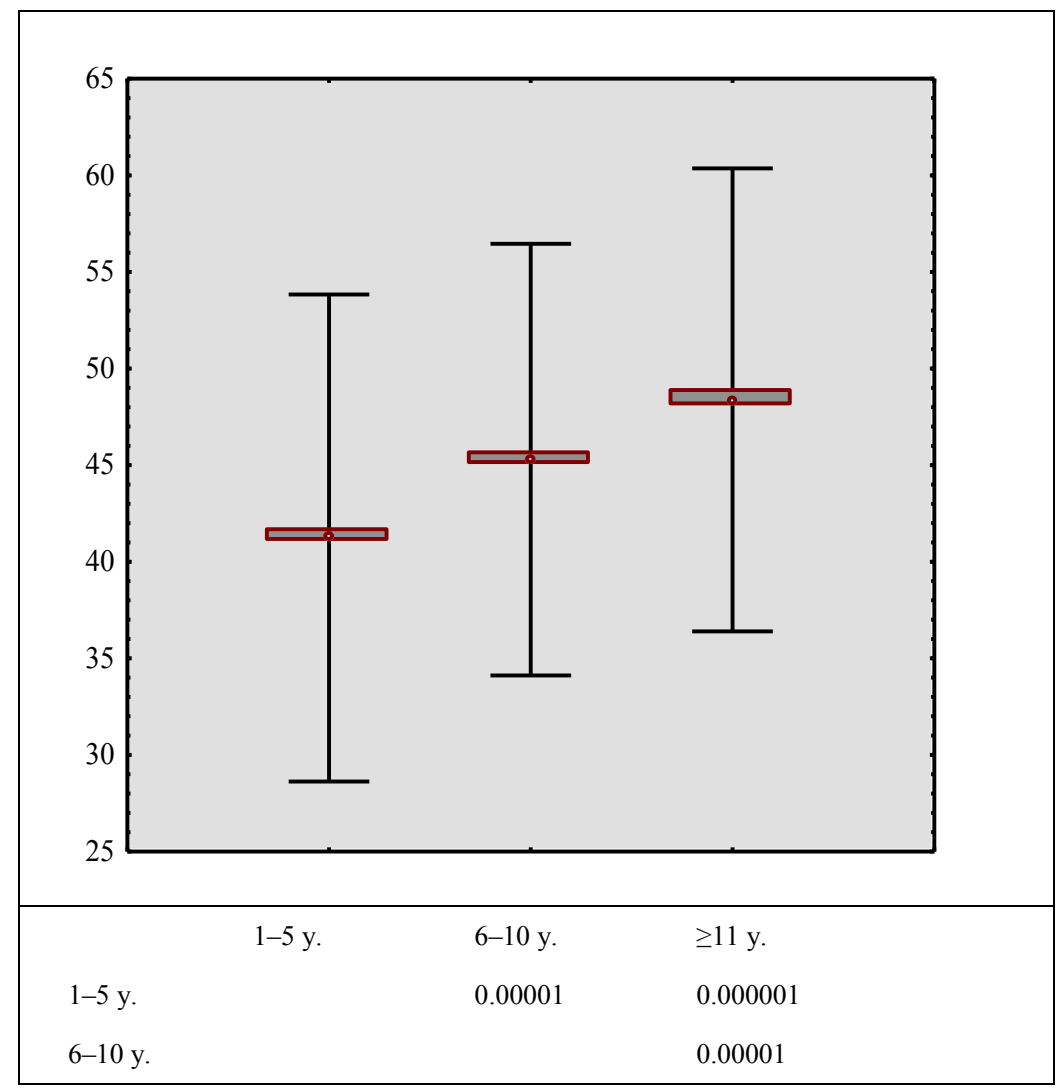

Fig. 3. The percentage volume of acini in dogs of different age (mean, standard error, standard deviation, and $\mathrm{P}$ value)

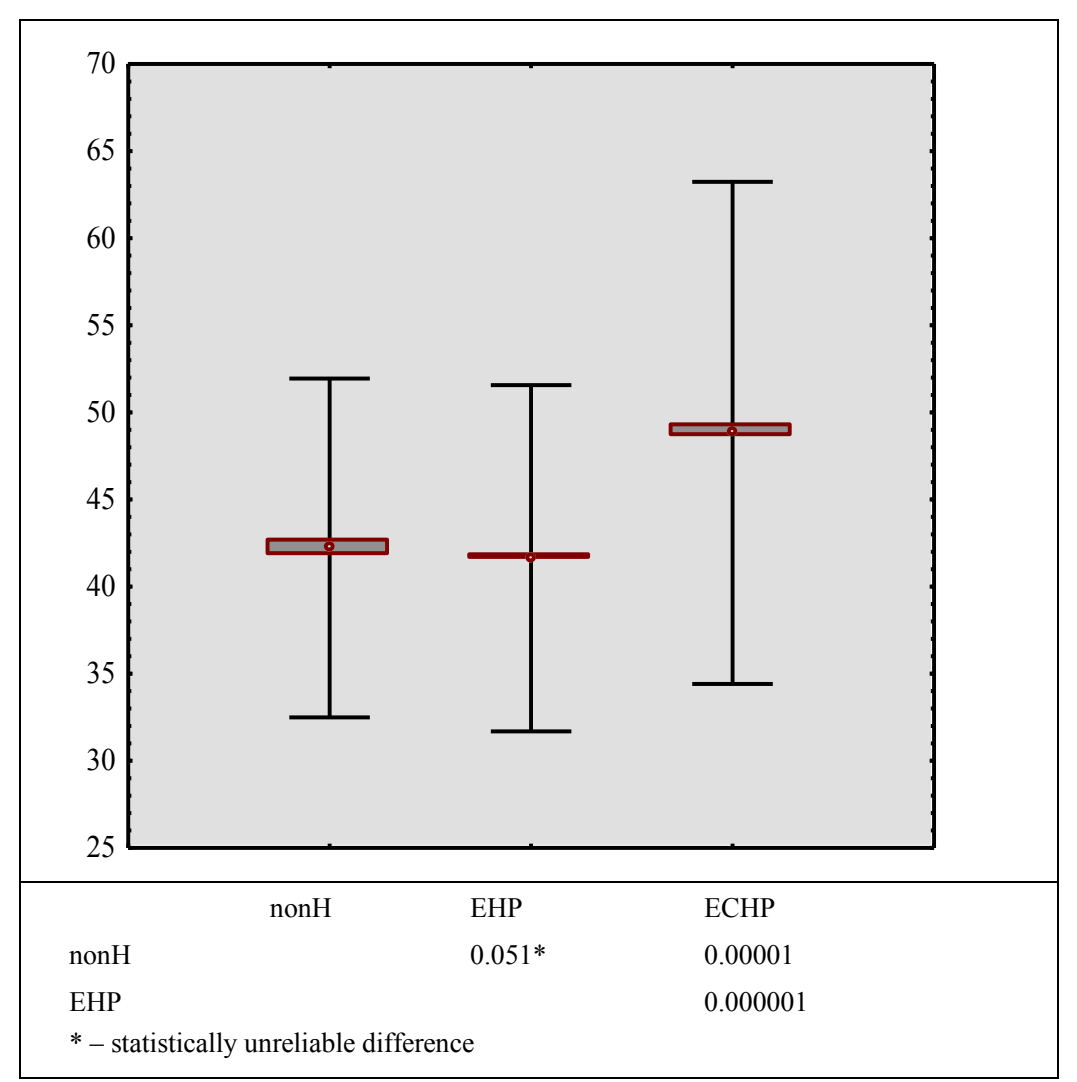

Fig. 4. The percentage volume of acini in nonhyperplastic and hyperplastic canine prostates (mean, standard error, standard deviation and $\mathrm{P}$ value) 


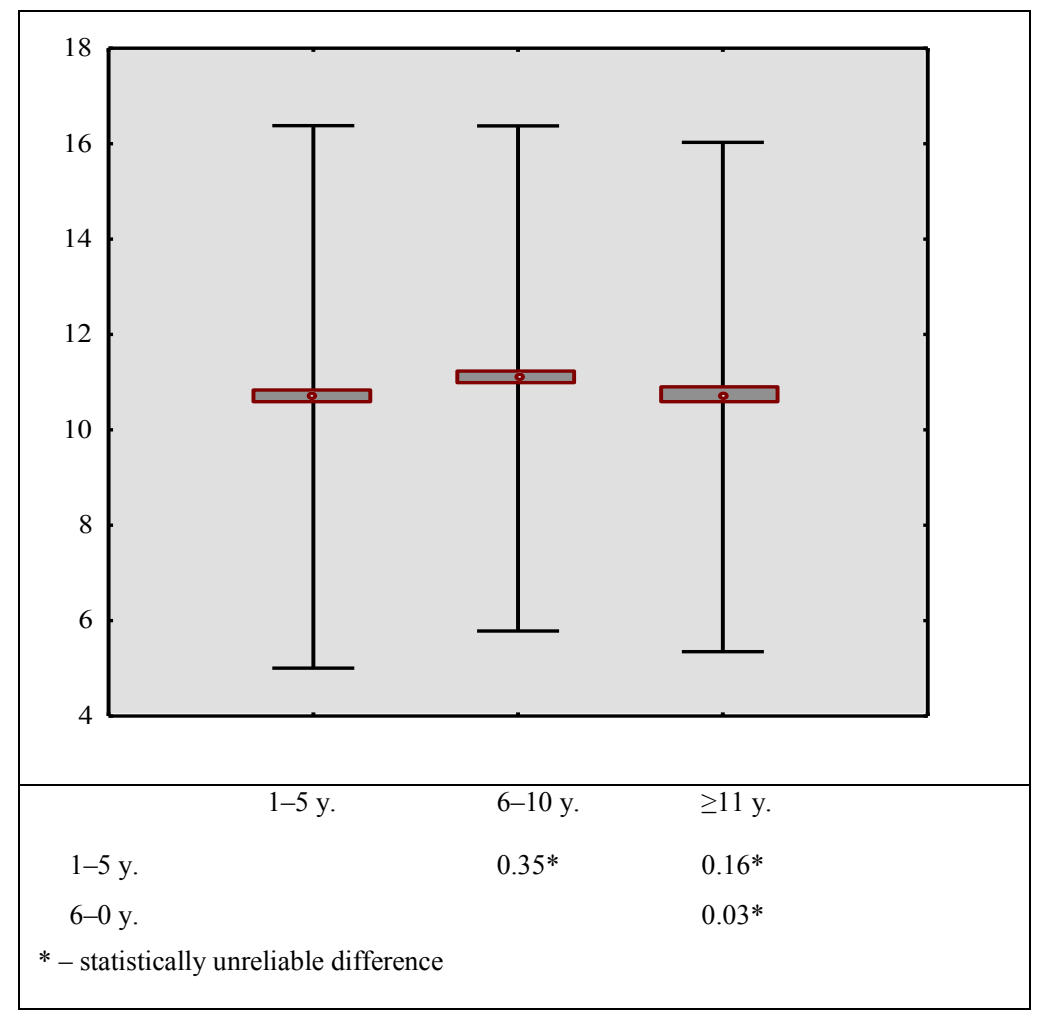

Fig. 5. The percentage volume of the interstitial collagen in different age dogs (mean, standard error, standard deviation, and $\mathrm{P}$ value)

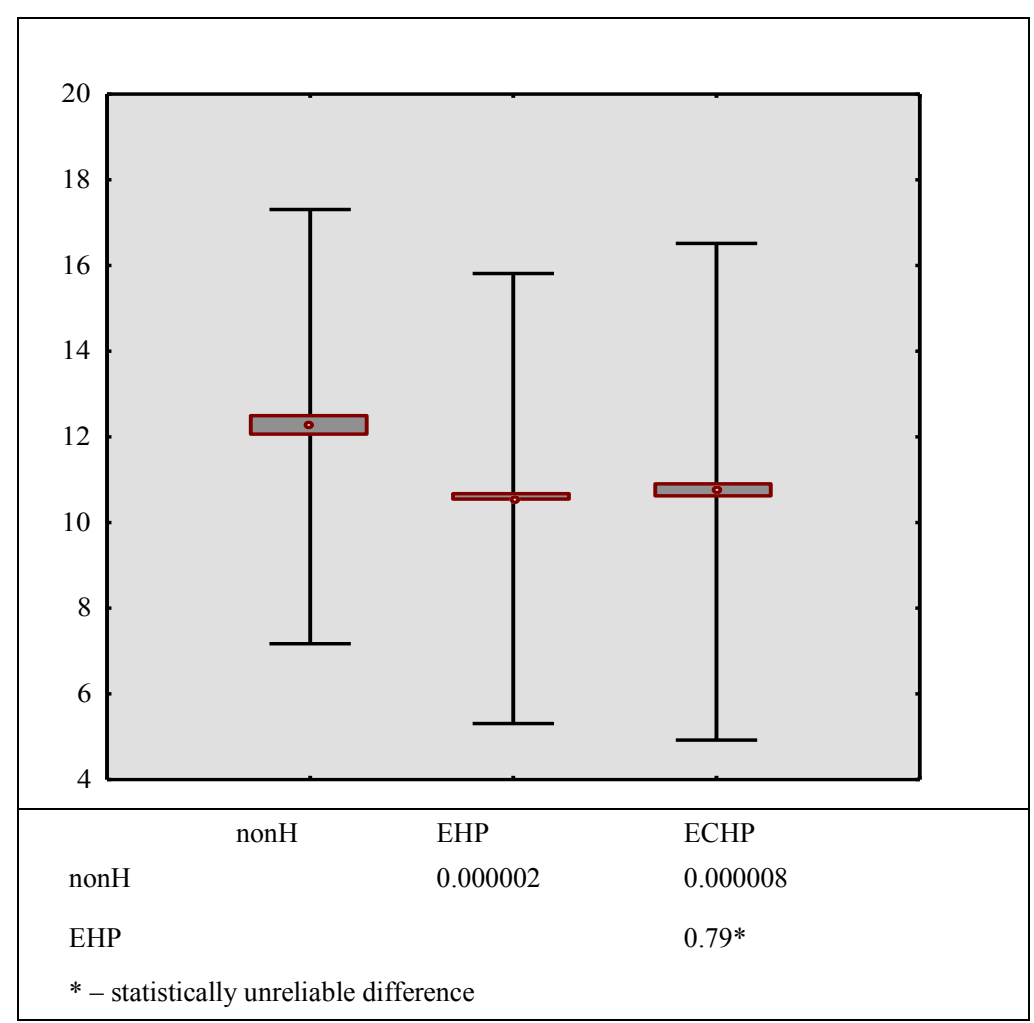

Fig. 6. The percentage volume of fibril collagen in nonhyperplastic and hyperplastic canine prostates (mean, standard error, standard deviation, and $\mathrm{P}$ value) 


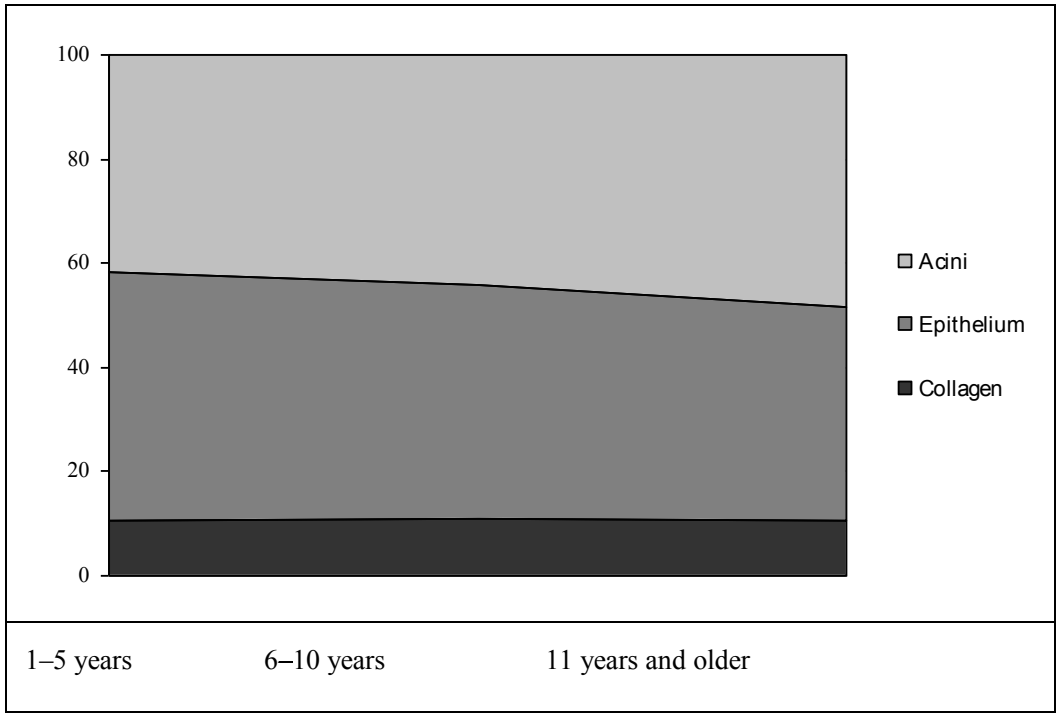

Fig. 7. The change of the percentage volume of collagen, epithelium, and acini in ageing dogs

It differed also significantly from cases of EHP $(\mathrm{P}<0.001)$. The percentage volumes of acini did not differ between the prostates with normal histology (42.6\%) and EHP (41.3\%) (Fig. 4). No statistically significant difference in collagen percentage volume was found across age groups. (Fig. 5).

Comparing the quantitative parameters of the prostates with the normal histological structure to those of the prostates with EHP and ECHP, the highest percentage $(12.1 \%)$ volume of fibril collagen was found in the prostates of normal histological structure and lower percentages were seen in cases of epithelial and epithelial cystic hyperplasia $(\mathrm{P}<0.01)$. According to our results, the percentage volumes of fibrillar collagen in EHP and ECHP were almost the same at $10.7 \%$ and $10.8 \%$ respectively $(\mathrm{P}>0.05)$ (Fig. 6).

Graphically, the change of percentage volume of collagen, epithelium, and acini with dogs' ageing is given in Fig. 7.

We found that the index of the prostates in ageing dogs increased from 1.245 in one-to-five-year-old dogs to 2.389 in ten-year-old and older dogs. Using the correlation method, the interrelation of prostate structures (epithelium, collagen, and acini) and the size of the glands was analysed. No significant interrelation $(\mathrm{P}>0.05)$ between epithelial percentage volume, collagen percentage volume, and the size of the gland was found. However, strong correlation was detected between acini percentage volume and the size of the prostate $(\mathrm{R}=0.54, \mathrm{P}<0.01)$.

\section{Discussion}

This study demonstrated that the percentage volume of epithelium decreases with age but the percentage volume of acini increases.

The percentage volume of epithelium was nowhere higher than in cases of EHP, nor anywhere lower than in cases of ECHP, in which cases the percentage volume of acini was also at its maximum. There were no differences between normal prostates and those with EHP regarding acini, however.

Prostatic hyperplasia in dogs appears to be pure proliferation of epithelial cells $(7,9,18)$. Our findings are also supported by Isaacs (9), who states that hyperplasia in the canine prostate involves more the glandular compartment than the stroma. The growth pattern observed in the examined dogs' prostates in the study of Zirkin and Strandberg (20) suggests that the normal prostate continues to enlarge in adult life, and the hyperplasia appears before the gland reaches its full development. It is clear from our study results that the percentage volume of fibrillar collagen does not change greatly with the ageing of dogs. According to our results, its volumes in EHP and ECHP were almost the same $(\mathrm{P}>0.05)$, and the highest volume was in the prostates with normal histological structure. In $\mathrm{BPH}$, the amount of stroma is relatively less than in ormal glands, and the septa appear somewhat attenuated $(14,20)$. In atrophic areas of benign complex hyperplasia, the amount of stroma, which is composed of both collagen and smooth muscle, is relatively increased $(14,20)$.

Other authors have pointed out that the canine prostate stromal part increases distinctly in BPH (9). Zirkin and Strandberg (20) concluded that proliferation of glandular and stromal components and increases in epithelial cell numbers and cell size result in prostatic enlargement during ageing. The index of the prostates in ageing dogs increased from 1.245 in one-to-five-year-old dogs to 2.389 in ten-year-old and older dogs. This finding is in agreement with that of other authors $(2,3)$. The glandular tissue volume (epithelial cells plus lumen) increases in ageing dogs $(5,20)$. Similarly, the results of Lowseth et al. (13) suggest that there is more stromal than glandular involvement in the dog. Their results suggest that the increase observed in the glandular component is primarily due to a cystic dilatation of the 
epithelial acini, but is not the result of an increase in the absolute volume of glandular epithelium. The relative lumen volume of the acini increases with age, which reflects the cystic nature of complex BPH (13). According to Lowseth et al. (13), the increases in weight and size of the prostate are primarily attributable to increases in the inflammatory and interstitial tissues, with the inflammation being located primarily within the interstitial tissues. We found that the percentage volume of collagen in the prostate does not change dramatically with age. According to the findings of our previous study (11), the collagen perimeter and decreasing number of collagen fibres show that collagen fibres undergo remodelling with age. Fibres of collagen in the canine prostate unite over time into thicker and more massive ones. The collagen fibres in the prostate of immature dogs are less abundant and thicker, and after sexual maturation they become more abundant and thinner (11).

In conclusion, through the ageing process the cystic formation progresses in the dog prostate, and the percentage volume of epithelium decreases. The percentage volume of epithelium increases in cases of epithelial hyperplasia, and decreases in cases of epithelial cystic hyperplasia. In contrast, the percentage volume of acini increases in cases of epithelial cystic hyperplasia and decreases in epithelial hyperplasia. The percentage volume of prostatic collagen did not change distinctly with advancing dog age and was higher in normal prostates than hyperplastic prostates (for both epithelial hyperplasia and epithelial cystic hyperplasia).

Conflict of Interests Statement: The authors declare that there is no conflict of interests regarding the publication of this article.

Financial Disclosure Statement: The present work was financially supported by the Department of Infectious Diseases, Veterinary Academy, Lithuanian University of Health Sciences.

Animal Rights Statement: The work was performed in compliance with Lithuanian animal welfare regulations and was approved by the Lithuanian Committee of Veterinary Medicine and Zootechnical Sciences.

Acknowledgements: We thank Mrs. Zita Stanionienè, an engineer-mathematician from the Laboratory of Cardiac Pathology, Institute of Cardiology, Lithuanian University of Health Sciences for her statistical analysis.

\section{References}

1. Bauzaitè N., Aniuliene A.: Enlarged prostate lesions of purebred and mongrel dogs. Med Weter 2003, 59, 686-690.
2. Cai R.F., Cui Y.G., Hua L.X., Jia Y., Ma D.Z., Wang X.H. Experimental research on spontaneous benign prostatic hyperplasia in old dogs. Zhonghua Nan Ke Xue 2003, 9, 651-653.

3. Chevalier S., McKercher G., Chapdelaine A.: Serum and prostatic growth-promoting factors for steroid-independent epithelial cells of adult dog prostate. Prostate 1991, 19, 207-220.

4. Gallardo-Arrieta F., Doll A., Rigau M., Mogas T., Juanpere N., García F., Morote J., Nuñez F., Abal M., Lloreta J., Reventós J.: A transcriptional signature associated with the onset of benign prostate hyperplasia in a canine model. Prostate 2010, 70, 1402-1412.

5. Gallardo-Arrieta F., Mogas T., Magán L., García M.A., García F., Abal M., Morote J., Serrano S., Reventós J., Lioreta J. Ultrastructural changes in prostate cells during hormone-induced canine prostatic hyperplasia. Ultrastruct Pathol. 2006, 30, 435-442.

6. Gottfried H.W., Brändle E., Hefty R., Mattfeldt T., Badura W., Vogel U., Hautmann R.E.: Laser therapy in dogs and humans is there a difference? Brit J Urol 1997, 79, 385-388.

7. Griffiths K., Eaton C.L., Harper M.E., Peeling B., Davies P.: Steroid hormones and the pathogenesis of benign prostatic hyperplasia. Eur Urol 1991, 20, 68-77.

8. Helpap B., Riede C.: Nucleolar and AgNOR-analysis of prostatic intraepithelial neoplasia (PIN), atypical adenomatous hyperplasia (AAH) and prostatic carcinoma. Pathol Res Pract 1995, 191, 381-390.

9. Isaacs J.T.: Common characteristics of human and canine benign prostatic hyperplasia. Prog Clin Biol Res 1984, 145, 217-234.

10. Jiang J., Chang H.L., Sugimoto Y., Lin Y.C. Effects of age on growth and ERbeta mRNA expression of canine prostatic cells. Anticancer Res 2005, 25, 4081-4090.

11. Juodziukyniene N., Aniuliene A., Pangonyte D.: Effect of age, hyperplasia and atrophy on collagen parameters in dog prostates. Polish J Vet Sci 2010, 13, 479-485.

12. Leav I., Schelling K.H., Adams J.Y., Merk F.B., Alroy J.: Role of canine basal cells in postnatal prostatic development, induction of hyperplasia, and sex hormone-stimulated growth; and the ductal origin of carcinoma. Prostate. 2001, 48, 210-224.

13. Lowseth L.A., Gerlach R.F., Gillett N.A., Muggenburg B.A.: Age-related changes in the prostate and testes of the beagle dog. Vet Pathol 1990, 27, 347-353.

14. Niu Y., Zhang I., Bai J., Yang H., Ma T.: Proliferation and differentiation of prostatic stromal cells. Brit J Urol Int 2001, 87, 386-393.

15. O'Shea J.D.: Studies on the canine prostate gland. I. Factors influencing its size and weight. J Comp Pathol 1962, 72, 321-331.

16. Polisca A., Troisi A., Fontaine E., Menchetti L., Fontbonne A. A retrospective study of canine prostatic diseases from 2002 to 2009 at the Alfort Veterinary College in France. Theriogenology 2016, 85, 835-840.

17. Prezioso D., Denis L.J., Klocker H., Sciarra A., Reis M., Lobel B., Dalibor P., Griffiths K.: Estrogens and aspects of prostate disease. Int J Urol 2007, 14, 1-16.

18. Sinowatz F., Schams D., Einspanier R., Arnold G., Pfeffelg M., Temmim-Bakers L. Amselgruberl W., Plendll J.: Cellular localization of fibroblast growth factor 2 (FGF-2) in benign prostatic hyperplasia. Histol Histopathol 2000, 15, 475-481.

19. Winter M.L., Bosland M.C., Wade D.R., Falvo R.F., Nagamani M., Liehr J.G.: Induction of benign prostatic hyperplasia in intact dog by near-physiological levels of 5-alphadihydrotestosterone and 17 beta-estradiol. Prostate 1995, 26, 325-333.

20. Zirkin B.R., Strandberg J.D.: Quantitative changes in themorphology of the aging canine prostate. Anatom Rec 1984, $208,207-214$. 